\title{
Lymphographic studies in acute lymphogranuloma venereum infection
}

\author{
A. O. OSOBA AND C. A. BEETLESTONE \\ From the Special Treatment Clinic and the Departments of Medical Microbology and Radiology, \\ University of Ibadan, Nigeria
}

\begin{abstract}
Summary
Lymphography, a radiological method of demonstrating lymphatic channels and nodes, has been used to investigate three cases of acute bubonic lymphogranuloma venereum (LGV). There is general agreement that LGV has a predilection for lymphatic channels and lymph nodes. However, very little is known of the extent of lymph node involvement in the early bubonic stage and whether there is merely a lymphangitis or complete lymphatic obstruction.

The present study was undertaken to determine the lymphographic appearance in acute bubonic LGV, the extent of lymphatic node involvement in early LGV, and the usefulness of the procedure in the management of LGV patients.

The buboes were not outlined by this procedure. The vessel phase of the lymphogram appeared normal, while the nodal phase showed a gradient of pathological involvement from the inguinal region lessening towards the lumbar nodes. The main drawbacks of lymphography in LGV are the difficulty of visualizing the lymphatics in the negroid skin and the lack of diagnostic criteria for inflammatory diseases of the lymphatic system. The lymphographic findings in LGV as described here may be regarded as typical of LGV but cannot be accepted as specific for LGV with a high degree of confidence. It is suggested that the procedure could be used for monitoring patients with the severe and late sequelae of LGV infection.
\end{abstract}

\section{Introduction}

Lymphography is the radiographic study of lymphatic vessels and lymph nodes. Since Kinmonth (1952,

Presented at the 14th Annual Conference of Radiologists of West Africa at Abidjan, February 6, 1976

Received for publication March 18, 1976

Address for reprints: Dr A. O. Osoba, M.D., Department of Medical

Microbiology, University of Ibadan, Nigeria
1954) described a convenient method of cannulating the lymph vessels and injecting water-soluble contrast medium, the procedure has become extensively used. Lymphography has been used in a variety of conditions in which the pathological process originates in or is associated with lymph nodes (Koehler, $1968 \mathrm{a}$, b). In lymphomas, the lymphographic appearance can be pathognomonic, hence much excellent work has been done in this field (Abrams, Takahashi, and Adams, 1968; Lee, 1968; Rosenberg, 1968). However, little work has been done on inflammatory conditions such as tuberculosis, syphilis and lymphogranuloma venereum (LGV), which produce lesions in lymph glands. Because lympho graphy is the only direct method of visualizing theo lymphatics and lymph nodes, and since it can? objectively evaluate the inaccessible pelvic and retroperitoneal lymph nodes (Koehler, 1968a), it was thought worthwhile to study some cases of LGV by this procedure.

LGV has a predilection for the lymphatic channels and lymph nodes, but very little is known of the extent of lymph node involvement in the early bubonic stage and it is uncertain whether the condition is merely a lymphangitis or causes a complete lymphatic obstruction.

This paper reports the results of a study of the lymphographic appearances in acute bubonic LGV, the extent of lymphatic and lymph node involvement in early LGV, and the usefulness of the procedure in the management of patients with LGV.

\section{Material}

The investigation was carried out on eight patients with acute classical bubonic LGV who had fluctuant unruptured buboes and had received no antibiotic therapy.

The clinical diagnosis of LGV was confirmed by the results Frei test and/or the LGV complement-fixation test (LGVCFT).

Direct lymphography was attempted in all eight patients but satisfactory lymphograms were obtained in only three.

Syphilis was excluded by the VDRL test and the FTA-200 test. 


\section{Method}

The procedure of Kinmonth (1952, 1954) was used with some minor modifications.

Methylene blue was injected into the web space of the great and second toes. This dye was taken up by the lymphatics draining the area.

A suitable vessel was isolated and cannulated. Lipoidal Ultra fluid was injected for a period of approximately $2 \mathrm{hrs}$. Dosage never exceeds $1 \mathrm{ml} . / \mathrm{kg}$. body weight.

Films were taken during injection of the lymph vessels and again $24 \mathrm{hrs}$ after the lymph nodes were filled.

The four standard positions to demonstrate inguinal and retroperitoneal nodes were used (antero-posterior supine, right and left oblique, and left lateral). This permits projection of lymphatics free of the vertebral bodies and serves to minimize superimposition of glands.

No complications were encountered by us during these procedures.

\section{Results}

Interpretation of radiographs

The criteria used in the interpretation of the radiographs were those accepted by several authors (Wiljasalo, 1976; Fischer, 1968; Viamonte, 1968; a, b; Wallace and Jackson, 1968; Wallace, Jackson, and Greening, 1962; Forström, Hannuksela, and Rauste, 1973).

The lymphatic chains were considered to be normal if they were not dilatated, tortuous, displaced, or with evidence of obstruction, and ran a course paralleling that of the arteries and veins. Lymph nodes were normal if they were:

(a) oval, elongated, or triangular and flattened; (b) of a homogenous reticular appearance with even distribution of the contrast material;

(c) with well-defined margins with the hilar area well demonstrated by a smooth indentation.

Rounded lymph nodes with a structure looser than normal were considered pathological. These were further divided according to their storage pattern. Area of various sizes devoid of contrast medium and with an appearance clearly different from the basic structure of the lymph node were regarded as filling defects.

Lymph glands showing enlargement, a rounded shape, and a relatively coarse structure were regarded as suggesting acute inflammatory reaction (Wiljasalo, 1965).

In the present study, anatomical and pathological interest was focused on the lymph vessels and nodes of the inguinal region, the pelvis, and the retroperitoneal space.

The main lymphographic findings and the clinical features of each are summarized in the Table.

Figs 1 and 2 show the lymphatic 'vessel phases' of Cases 1 and 3. The 'nodal phases' are illustrated in Figs 3 to 5 .

There was a gradient of pathology which decreased from the inguinal region to the lumbar nodes. There were large masses of pathological lymph nodes showing evidence of inflammatory involvement in the inguinal regions in all cases. The buboes clinically demonstrable were not outlined by the lymphograms and contrast was not taken up by these pathological nodes and abscesses.

TABLE Clinical features and lymphographic findings in three cases of acute lymphogranuloma venereum

\begin{tabular}{|c|c|c|c|c|c|c|c|}
\hline \multirow{3}{*}{ Case no. } & \multirow{3}{*}{$\begin{array}{l}\text { Clinical } \\
\text { features }\end{array}$} & \multirow{3}{*}{ Frei test } & \multirow{3}{*}{$\begin{array}{l}\text { Highest } \\
\text { LGVCFT } \\
\text { titre }\end{array}$} & \multicolumn{4}{|c|}{ Lymphographic findings } \\
\hline & & & & \multirow[t]{2}{*}{ Vessel phase } & \multicolumn{3}{|l|}{ Nodal phase } \\
\hline & & & & & Inguinal & Iliac & Lumbar \\
\hline $\begin{array}{l}\text { Case 1 } \\
\text { (Figs } 1 \\
\text { and 3) }\end{array}$ & $\begin{array}{l}\text { Primary penile } \\
\text { lesion with left } \\
\text { inguinal bubo } \\
1 \text { week's } \\
\text { duration } \\
\text { Incubation } \\
\text { period } 3 \text { wks }\end{array}$ & +ve & $1 / 64$ & $\begin{array}{l}\text { Normal } \\
\text { No obstruction } \\
\text { or displacement }\end{array}$ & $\begin{array}{l}\text { Bilateral oval } \\
\text { enlarged coarse } \\
\text { granular glands } \\
\text { Central filling } \\
\text { defects }\end{array}$ & $\begin{array}{l}\text { Bilateral } \\
\text { moderately } \\
\text { enlarged } \\
\text { granular glands } \\
\text { No filling } \\
\text { defects }\end{array}$ & Normal \\
\hline $\begin{array}{l}\text { Case } 2 \\
\text { (Fig. 4) }\end{array}$ & $\begin{array}{l}\text { Primary penile } \\
\text { lesion with } \\
\text { right inguinal } \\
\text { bubo } \\
4 \text { days' duration } \\
\text { Incubation } \\
\text { period } 3 \text { wks }\end{array}$ & +ve & $1 / 32$ & $\begin{array}{l}\text { Normal } \\
\text { No obstruction } \\
\text { or displacement } \\
\text { on right side } \\
\text { Cannulation } \\
\text { on left side } \\
\text { unsuccessful }\end{array}$ & $\begin{array}{l}\text { Right side } \\
\text { rounded } \\
\text { enlarged } \\
\text { granular glands } \\
\text { Peripheral and } \\
\text { central filling } \\
\text { defects }\end{array}$ & $\begin{array}{l}\text { Some glands } \\
\text { rounded and } \\
\text { granular } \\
\text { Central filling } \\
\text { defects } \\
\text { Other normal } \\
\text { glands present }\end{array}$ & $\begin{array}{l}\text { Some glands } \\
\text { rounded and } \\
\text { granular } \\
\text { Replacement or } \\
\text { filling defects } \\
\text { Other normal } \\
\text { glands present }\end{array}$ \\
\hline $\begin{array}{l}\text { Case } 3 \\
\text { (Figs } 2 \\
\text { and } 5 \text { ) }\end{array}$ & $\begin{array}{l}\text { Primary penile } \\
\text { lesion with right } \\
\text { inguinal bubo } \\
1 \text { week's } \\
\text { duration } \\
\text { Incubation } \\
\text { period } 3 \text { wks }\end{array}$ & $\begin{array}{l} \pm \\
\text { (Induration } \\
\text { in both } \\
\text { control and } \\
\text { test arms) }\end{array}$ & $1 / 16$ & $\begin{array}{l}\text { Moderate } \\
\text { obstruction } \\
\text { with dilatation } \\
\text { of lymphatics } \\
\text { on right side } \\
\text { No displace- } \\
\text { ment of nodes } \\
\text { or vessels }\end{array}$ & $\begin{array}{l}\text { Mass of enlarged } \\
\text { rounded glands } \\
\text { Markedly } \\
\text { coarsened } \\
\text { storage pattern } \\
\text { Some loss of } \\
\text { marginal sinus } \\
\text { Filling defects }\end{array}$ & $\begin{array}{l}\text { Similar to } \\
\text { inguinal glands } \\
\text { but only to a } \\
\text { lesser degree }\end{array}$ & $\begin{array}{l}\text { Moderate } \\
\text { enlargement } \\
\text { and granularity } \\
\text { Filling defects }\end{array}$ \\
\hline
\end{tabular}

$\pm=$ Equivocal 


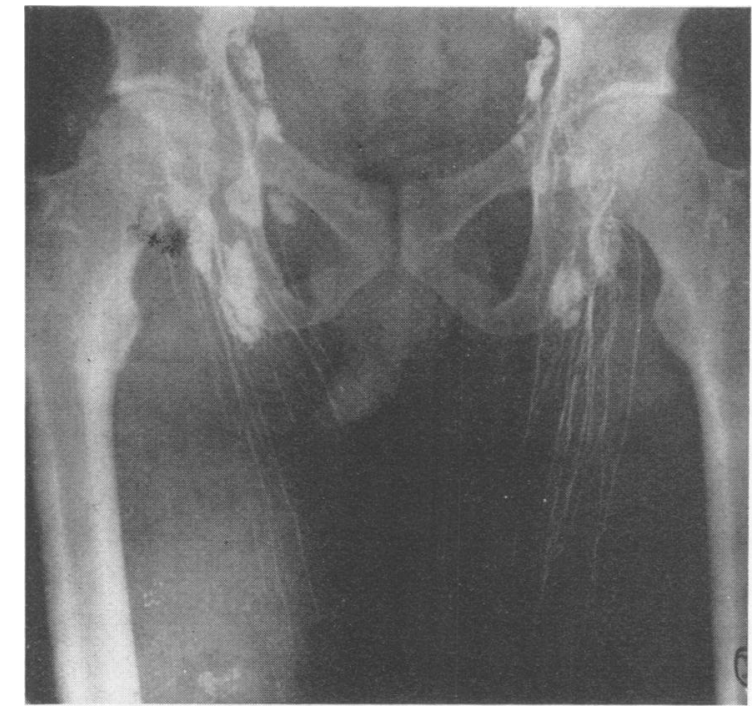

FIG. 1 Case 1. Filling of lymph vessels and nodes

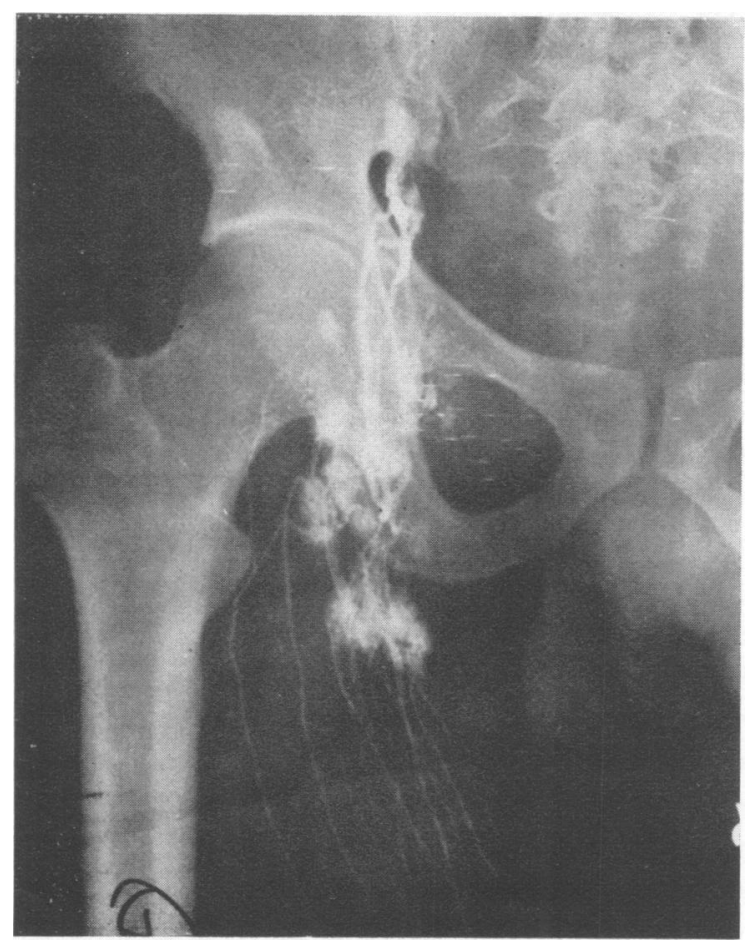

FIG. 2 Case 3. Lymphatic vessel phase, showing moderate obstruction with dilatation of lymphatics

\section{Discussion}

In the clinical literature of the past two decades increasing attention has been directed to the use of lymphography in the detection and management of

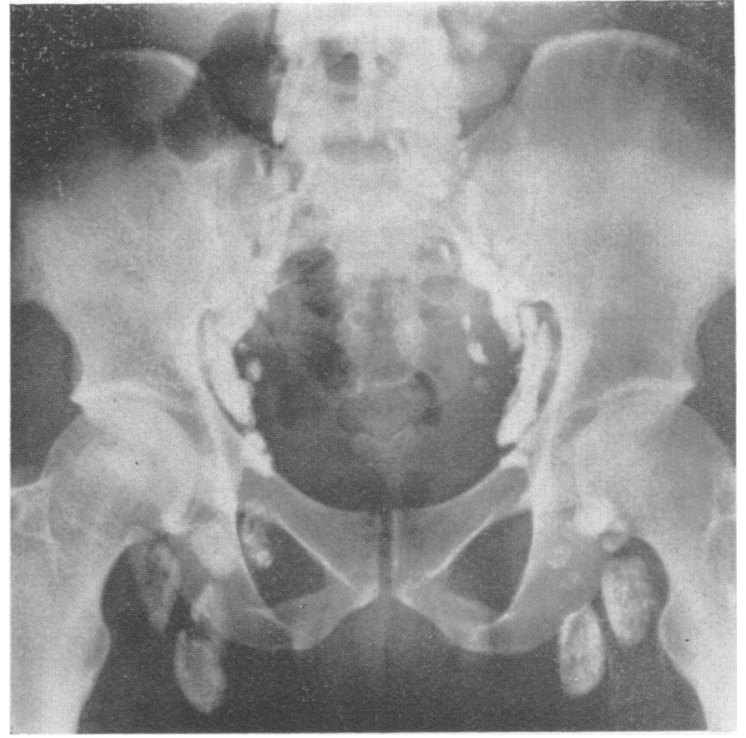

FIG. 3 Case 1. Nodal phase, showing oval, enlarged, coarse and granular glands with central filling defects on both sides. Bubo not outlined.

primary and secondary neoplastic involvement of the lymphatic system (Howett and Elmendorf, 1965)? However, published data on the lymphographico appearances of inflammatory conditions, such as tuberculosis and LGV, are lacking. A possible explanation may be the lack of suitable clinical material. The main limiting factor in our study has been the relatively small numbers of patients with unruptured buboes and of patients that had not had antibiotics before consultation.

Lymphography in this small series of patients has provided the visualization of lymph nodes in the inguinal, iliac, and lumbar regions and an opportunity to assess the procedure as a possible diagnostic technique in LGV.

In the filling phase the lymphatic channels appear normal except for one case with evidence of obstruction showing dilatation of the lymphatic channels on the same side as the bubo. This may be a result of the lymphangitis known to occur in LGV.

More interesting findings were observed in the nodal phase. There was a gradient of pathological involvement, more severe in the inguinal nodes and lessening in the lumbar nodes.

In the inguinal region there was a conspicuous failure of the lymphogram to outline the bubo itself. All our cases investigated by lymphography had the characteristic inguinal bubo of LGV. This may have been a result of the periadenitis and perinodal fibrosis known to occur in LGV (Smith and Custer, 1950) which has served to obstruct the flow of contrast and to prevent the outlining of the bubo. 


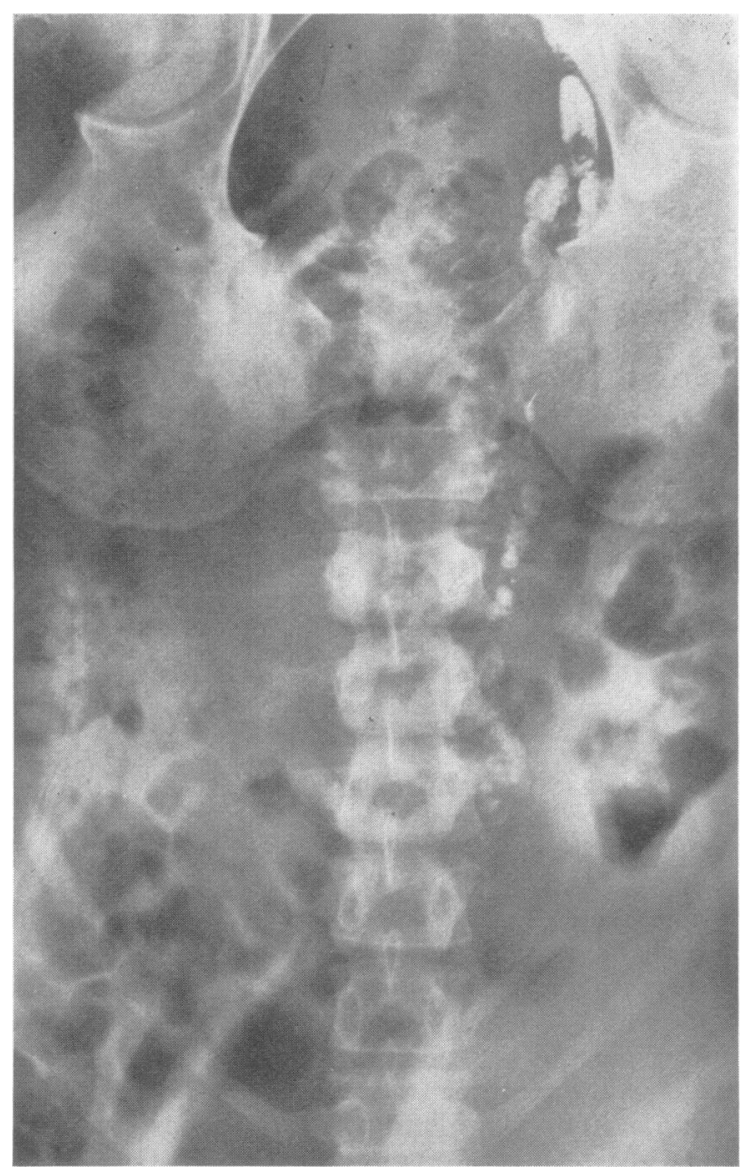

FIG. 4 Case 2. Nodal phase, showing inguinal glands, rounded, enlarged, and granular with peripheral and central filling defects. Gradient of pathological involvement lessening towards the lumbar glands. Bubo not outlined.

Furthermore, there was no evidence of the opening of a collateral spread of channels to or from the bubo itself, suggesting that the lymphatic channels outlined were only those draining the nodes whose functions had not been seriously affected. Support for this explanation may be obtained from a similar situation reported by Howett and Elmendorf (1965). When a chain of nodes is replaced by carcinomatous disease, collateral spread of contrast medium is not usually seen. Although the neoplastic process can not be directly compared with the inflammatory process, there is replacement of normal lymphatic tissue by non-functional tissue in both.

Another significant point observed was that, although the bubo occurred on only one side, the pathological glandular involvement could be demonstrated on both sides in glands not normally clinically

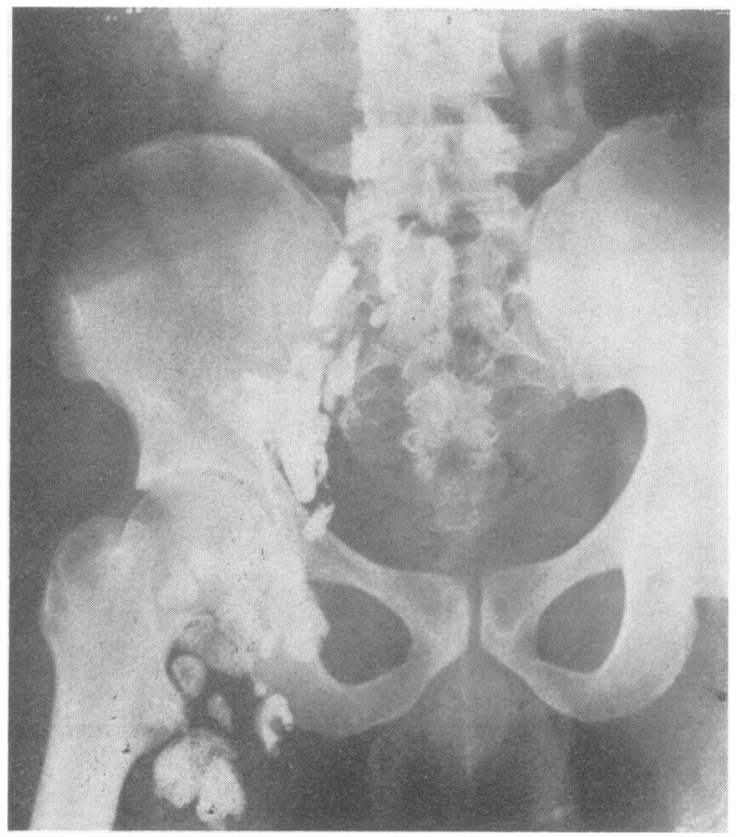

FIG. 5 Case 3. Nodal phase, showing a mass of enlarged rounded glands with markedly coarsened storage pattern and filling defects. Gradient of pathological involvement lessens towards the lumbar glands. Bubo not outlined.

palpable. This fact is illustrated by Case 1 (Figs 1 and 3). This suggests that infection could possibly spread through anastomoses between the lymphatics of both sides. In practice, attention would therefore need to be paid to the unaffected side as well, by careful palpation of the glands in the follow-up of patients under treatment.

On the lymphogram, the inguinal glands were enlarged with a coarse storage pattern and filling defects. Viamonte (1968a) suggested that filling defects in inflammatory conditions might be correlated with fibrosis, infiltration, or replacement. This suggestion conforms with the histological picture of nodes infected with LGV showing characteristic stellate abscesses which later coalesce to form a bubo with perinodular fibrosis (Smith and Custer, 1950).

The iliac nodes in all cases showed pathological involvement. They were enlarged with architectural changes and filling defects (Table and Figs 3, 4, and 5).

Although the pathological changes were less marked than those in the inguinal nodes, it confirms the hypothesis of previous authors (Stokes, Beerman, and Ingraham, 1944; Galbraith, Graham-Stewart, and Nicol, 1957; Alergant, 1957) that iliac glands were usually involved in the inguinal lymphangitis. 
Although some authors have reported that they were able to palpate these iliac glands (Alergant, 1957), our experience has been to the contrary. Palpation of these glands is extremely difficult through the pelvic organs and with the tenderness of the bubo.

In two of the lymphograms, the lumbar nodes showed evidence of enlargement, coarsening of the storage pattern, and filling defects. These findings are interesting but unexpected (Figs 4 and 5). These retroperitoneal glands are not easily palpable clinically and hence reports of lymph node involvement in LGV have been confined mainly to the inguinal glands. It appears from these lymphograms that in the bubonic phase, at least, the lumbar glands are involved in LGV lymphadenitis. This observation, which has not been previously recorded, may prove useful in following up those patients in whom the bubo has disappeared, or in chronic cases of LGV (e.g. recto-vaginal fistula, intestinal obstruction, and esthiomene) that must be maintained on long-term therapy with tetracycline.

Although the diagnostic criteria have been well established for lymphomas (Fischer, 1968; Wallace and Jackson, 1968; Abrams and others, 1968; Koehler, 1968a, b; Rauste, 1972; Viamonte, Altman, Parks, Blum, Bevilacqua, and Recher, 1963), this has not been the case with inflammatory diseases such as tuberculosis, syphilis, and LGV. The lymphographic pictures illustrated were obtained in acute cases of LGV, but cannot be regarded as necessarily specific to LGV. These lymphographic appearances would need to be differentiated from those in tuberculosis, non-specific reactive hyperplasia of the lymph nodes, and other tropical adenopathies, which are all very common in tropical and developing countries. A larger and more detailed series is required to clarify the diagnostic paramenters in LGV.

Lymphography can be used to demonstrate retroperitoneal involvement in the more serious cases of LGV and to monitor therapeutic response in cases of rectal stricture, rectovaginal fistulae, and esthiomene. The demonstration of lymphatic metastasis could be important in showing neoplastic changes superimposed on, or following, longstanding LGV. A drastic change in therapy and prognosis will be indicated in such a case.

Lymphography is of greater value than palpation of the lymph nodes, especially of the pelvis and retroperitoneal space; it is helpful in the management of individual cases; it offers a means of assessing therapeutic response , and it assists prognosis, particularly when neoplastic degeneration has occurred.

This study was supported by the University of Ibadan Senate Research Fund and the Wellcome Foundation which are gratefully acknowledged.

\section{References}

Abrams, H. L., TAKahashi, M., and Adams, D. S. (1968) Cancer chem. Rep., 52, 157

Alergant, C. D. (1957) Brit. F. vener. Dis., 33, 47

FISCHER, H. W. (1968) Cancer chem. Rep., 52, 119

ForströM, L., Hannuksela, M., and Rauste, J. (1973) Acta Derm. venereol. (Stockh.), 53, 347

Calbraith, H.-J. B., Graham-Stewart, C. W., and Nicol, C. S. (1957) Brit. med. F., 2, 1402

HowetT, M., and Elmendorf, E. A. (1965) Obstet. and Gynec., 26, 34

KinMontH, J. B. (1952) Clin. Sci., 11, 13

- (1954) Ann. roy. Coll. Surg. Engl., 15, 300

KoehLeR, P. R. (1968a) Cancer chem. Rep., 52, 171

- (1968b) Ibid., 52, 77

LEE, B. J (1968) Ibid, 52, 205

Rauste, J. (1972) Acta Radiol., Suppl. 317

Rosenberg, S. A. (1968) Cancer chem. Rep., 52, 213

SMITH, E. B., and CUSTER, R. P. (1950) f. Urol., (Baltimore 63, 546

Stokes, J. H., Beerman, H., and Ingraham, N. R. (1944) 'Modern Clinical Syphilology', 3rd ed. Saunders, Philadelphia

Viamonte, M. (1968a) Cancer chem. Rep., 52, 147

(1968b) Ibid., 52, 65

- , Altman, D., Parks, R., Blum, E., Bevilacqua, M., and ReCHER, L. (1963) Radiology, 80, 903

Wallace, S., and JACKson, L. (1968) Cancer chem. Rep., 52,125

$\longrightarrow,-$, and GreEning, R. R. (1962) Amer. F. Roentgenol., 88, 97

WiLjasalo, M. (1965) Acta Radiol., Suppl. 247 